\title{
Construindo um referencial teórico- metodológico para entender os impérios midiáticos brasileiros
}

\section{Building a theoretical-metodologic approach to understand the Brazilian midiatics empires}

Henrique Moreira'

\section{Resumo}

Este trabalho descreve o caminho percorrido pelo autor na busca de um referencial teórico-metodológico que dê sustentação a pesquisas que busquem estabelecer a relação entre as estratégias políticas e econômicas de dois dos principais impérios midiáticos brasileiros (Diários Associados e Organizações Globo), seus discursos jornalísticos e suas escolhas editoriais. Nesse percurso, o artigo revê as principais questões acerca da formação de um campo específico do conhecimento relacionado à Comunicação e às dificuldades na construção de uma epistemologia que abrigue a Comunicação como disciplina. Propõe ainda utilizar como referencial teórico os conceitos formulados por Max Weber no que diz respeito a uma sociologia da imprensa e à abordagem metodológica de "tipo ideal”. O artigo propõe, também , apoiar teoricamente a pesquisa nos postulados contidos na disciplina "Economia das mídias", principalmente naqueles defendidas por Augey e Rebillard. A expectativa é de que a pesquisa venha a contribuir para que se aprofunde o conhecimento a respeito dos meios de comunicação e também sua ação no âmbito da história política e social brasileira.

Palavras-chave: Sociologia do jornalismo. Economia midiática. Tipo ideal. História do jornalismo.

\begin{abstract}
This paper describes the path that was envisioned by the author in searching a theoretical and methodological approach to support researches which object is the relationship between the political and economic strategies designed by two among the more preeminent Brazilian Media Empires (Diários Associados e Organizações Globo) and its journalistic discourses and editorial choices. In this sense, the article reviews the most important issues involved in building a specific knowledge field called Communications and its epistemology. The paper also proposes as theoretical reference to the research the concepts of rational understanding of the historic movement, formulated by Max Weber, initially considering specific practices (as the press) and his concept of "Ideal Type". The expectation is that the project shall contribute to deepen the communication research understanding about the media and its influence to the Brazilian political and social history.
\end{abstract}

Keywords: Journalism sociology. Media economics. Ideal type. Journalism history. 


\section{Introdução}

O presente artigo resultou da reflexão do autor em torno de questões que sugerem a existência de uma relação entre estratégias políticas e econômicas e as linhas editoriais de grandes conglomerados jornalísticos no Brasil e de como apoiar esse tipo de pesquisa do ponto de vista teórico-metodológico.

Historicamente, predomina junto à imprensa brasileira um caráter instrumental que quase sempre a afasta dos interesses da sociedade e a mantém como elemento-chave de projetos políticos, tanto dos que apoiam os mais diferentes modelos de governo quanto dos que sustentam a mais feroz oposição a esses mesmos governos.

Mas há algo que diferencia dois dos mais importantes grupos midiáticos brasileiros (Diários Associados e Organizações Globo) daqueles que investiam nos jornais como elemento de apoio aos seus projetos comerciais. Nesse caso, a ação jornalística desses veículos ficava restrita a tais interesses. Demarcados os compromissos e os limites da linha editorial, as mensagens eram construídas sem que houvesse a preocupação em esconder preconceitos, posições políticas e, até mesmo, visões de mundo embotadas pelo racismo.

\begin{abstract}
Não era o lucro o que Alves de Lima² ${ }^{2}$ rocurava primordialmente ao comprar as Folhas. Para ser mais precisa, o lucro ele buscava nas suas atividades agrocomerciais, ligadas diretamente ao café. É claro que a promoção dos interesses desse setor da burguesia cafeeira através do jornal tinha como objetivo trazer mais lucros a tal grupo. Mas não era a empresa Folha da Manhã que deveria prover diretamente esses lucros. Não era o lucro do jornal o que mais interessava a Alves de Lima. Esse fato é importante porque afetava a relação entre o jornal enquanto mensagem e o jornal enquanto empresa (TASCHNER, 1992, p. 54).
\end{abstract}

Dentre os mais importantes empreendedores da nossa indústria midiática destacam-se os nomes de Assis Chateaubriand e Roberto Marinho. Embora suas ações tenham se dado em diferentes contextos políticos, os dois têm em comum o fato de terem construído seus conglomerados econômicos, compostos por uma diversidade de empresas de diferentes setores da economia, tendo como ponto de partida organizações jornalísticas. Esse fato se

2 Octaviano Alves de Lima, rico empresário paulista, cafeicultor, adquiriu os jornais "Folha da Manhã" e "Folha da Noite", em 1930. constitui, sem dúvida, em um fenômeno interessante que merece ser compreendido a partir de uma análise isenta, sustentada por uma exaustiva pesquisa que investigue as condições em que esses impérios foram erguidos.

Desvendar a maneira pela qual as maiores empresas de mídia do Brasil construíram suas estruturas, consolidaram-se, estabeleceram alianças e compromissos no campo político nos ajudará também a compreender suas escolhas editoriais e a construção de seus discursos jornalísticos. A partir desse estudo, será possível, ainda, entender algumas das "[...] características fundamentais do setor, como a sua grande concentração, sua ampla e contínua expansão, o que inclui ramificações regionais e locais, e a influência que exercem na elaboração de políticas públicas para o setor.” (CABRAL, 2009, p. 9).

\section{Para que servem as teorias?}

Essa questão é recorrente a todos os que se aventuram pelos desafiadores caminhos da pesquisa científica: como ouvir a intuição? De que maneira é possível ordenar o pensamento? Como vencer a especulação e explicar um fenômeno? E essa tentativa de ordenar não acabaria por reduzir o entendimento desse mesmo fenômeno? Como distinguir se o que está diante do pesquisador é uma conclusão lógica, enunciada de maneira singular, coerente, passível de ser posta à prova ou apenas um "amontoado de ruínas", sem o apoio de uma situação-problema como normalmente ocorre aos filósofos? (POPPER, 2008, p. 23).

Ao tentar estabelecer um lugar específico para a Comunicação entre as epistemologias contemporâneas, Luiz C. Martino constata a “[...] pouca sensibilidade dessa área para os problemas da fundamentação dos conhecimentos aí produzidos”. E completa, registrando que, para o estudo da questão epistemológica comunicacional, é preciso apoiar-se em dois pontos: “[...] a) a aceitação implícita de pressupostos incompatíveis com a instauração de um debate epistemológico; b) as confusões do tratamento epistemológico com o das outras disciplinas que distinguimos" (MARTINO, 2003, p. 84).

A tradição da pesquisa em Comunicação tem se apoiado, ao longo de mais de um século, em diversas disciplinas ligadas às Ciências Sociais, como a Sociologia, a Psicologia e a Antropologia; relacionadas às Ciências 
Naturais, como a Biologia e a Física; à Matemática; às Ciências da Linguagem (Linguística e Semiótica) e outras áreas do conhecimento. Com isso, virou lugar comum afirmar que a Comunicação constitui-se num saber interdisciplinar, ou seja, situa-se como uma "ciência encruzilhada" (MARTINO, 2006, p. 39).

Mesmo com essa diversidade de abordagens (ou, quem sabe, até por causa dela), a definição de um objeto específico da Comunicação encontra resistências. As diferentes abordagens utilizadas pelos teóricos na tentativa de definir um campo comunicacional esbarram, invariavelmente, na falta de um objeto de estudo com características específicas ligadas à Comunicação.

O termo "comunicação" é consensualmente aplicado ao ato de estabelecer uma relação, seja entre organismos vivos, entre objetos ou entre seres humanos. Apesar de haver uma tradição de estudos relacionados à Comunicação, que remonta ao final do século XIX, contemplando desde uma visão generalizada do fenômeno comunicacional até a troca simbólica entre seres humanos, foi com os estudos relacionados ao surgimento da sociedade de massa que o campo teórico da Comunicação avançou na sua tentativa de definir uma epistemologia própria. Com isso, a pesquisa em Comunicação acabou por eleger a comunicação mediática (aquela em que há a intervenção de um meio tecnológico) como a que tem a melhor possibilidade de vir a se constituir no objeto de estudo específico da Comunicação. Isso colocou os meios de comunicação no centro das atenções dos pesquisadores, que passaram a analisar suas características, seus efeitos, sua organização e o seu alcance.

Como foco dos estudos que podem vir a constituir a Comunicação como disciplina, os veículos de comunicação têm sido analisados a partir de muitos aspectos, como registra Mauro Wolf: “[...] regulamentações legislativas [...]; intrincadas operações financeiras [...]; episódios retumbantes acerca da não realização de um programa considerado 'incômodo'; crises, quedas e triunfos" (WOLF, 2001, p. 13).

Por outro lado, esses meios foram pouco estudados a partir de uma perspectiva histórica, principalmente no que concerne à sua institucionalização, aos aspectos econômicos e políticos que permitiram que avançassem e assumissem o papel de elemento central dessa sociedade complexa também chamada de sociedade mediática.

\section{Uma proposta de pesquisa histórica para o jornalismo brasileiro}

Desvendar a maneira pela qual as maiores empresas midiáticas brasileiras construíram suas estruturas e se consolidaram como entes econômicos, estabeleceram alianças e compromissos no campo político, poderá levar à compreensão, também, de suas escolhas editoriais e da construção de seus discursos jornalísticos.

Ao longo da história, são inúmeros os exemplos da ação política da imprensa em apoio a grupos ou pessoas, em detrimento dos interesses legítimos da sociedade. Para tanto, estabeleceram-se alianças estratégicas entre as forças políticas e os donos da mídia, ora com o intuito de manter o poder, ora visando alcançar o poder.

Na história midiática do Brasil, os nomes de Assis Chateaubriand e Roberto Marinho têm grande destaque. Embora parcela considerável de suas ações tenha se dado em diferentes contextos políticos, os dois têm em comum o fato de terem construído seus conglomerados econômicos, compostos por uma diversidade de empresas de diferentes setores da economia (laboratórios farmacêuticos, empresas siderúrgicas, bancos, financeiras e muitas outras), tendo como ponto de partida empresas de comunicação.

Mas esses dois personagens possuíam, também, características pessoais bastante divergentes. Enquanto Chateaubriand buscava, constantemente, o protagonismo político e social, conforme descrevem várias fontes que se ocuparam de sua trajetória pessoal (MORAIS, 1995), Marinho, ao contrário, preferia agir nos bastidores, tratando de se aproximar do poder sem se expor abertamente (SILVA, 1985). E essa diferença de comportamento também pode ajudar a construir modelos de análise que permitam identificar os interesses, as estratégias e as opções políticas de cada uma dessas personagens e de que forma essas escolhas se fazem presentes na produção jornalística de seus principais veículos.

Outro elemento importante que pode ser discutido diz respeito à própria evolução histórica da economia brasileira. É preciso levar em consideração que o surgimento e a consolidação desses conglomerados midiáticos coincidem com mudanças estruturais no modelo econômico do país que introduziram as condições essenciais para o desenvolvimento de uma economia capitalista. Essa nova configuração da economia brasileira exigiu uma grande disponibilização de recursos, o que só foi 
possível a partir do aporte de capital internacional. A comunicação, como já ocorrera em outros países de economia mais avançada, torna-se, então, elemento-chave para garantir um ambiente econômico favorável ao uso intensivo desse capital externo, permitindo o nascimento dos primeiros conglomerados midiáticos brasileiros.

Ao buscar compreender as questões relacionadas à gênese econômica desses impérios, abre-se a perspectiva de contribuir para ampliar nosso conhecimento a respeito da economia do jornalismo, tema ainda pouco explorado. Isso poderá ser útil no desenvolvimento de novos referenciais teóricos para analisar os meios de comunicação:

[...] instituições que exercem uma atividade chave que consiste na produção, reprodução e distribuição de conhecimentos [...] conhecimentos que podem dar sentido ao mundo, moldam a nossa percepção e contribuem para o conhecimento do passado e para dar continuidade à nossa compreensão presente. (McQUAIL, 1983 apud WOLF, 2001, p. 17).

\section{Buscando um referencial teórico}

A primeira grande dificuldade na definição de um referencial teórico capaz de dialogar e dar conta desse tipo de objeto diz respeito à própria singularidade que envolve os estudos relativos à Comunicação. Se pensarmos em quanto é difícil definir esse fenômeno, nas divergências que se evidenciam no momento em que somos levados a estabelecer um sentido para um termo tão impregnado de significados (polissêmico), damo-nos conta da grandiosidade da tarefa que temos diante de nós.

Do ponto de vista histórico, a tradição da pesquisa em Comunicação é marcada por uma diversidade de abordagens e de autores que partem dos estudos de Mass Communication (de tradição norte-americana); passam pela Teoria da Informação elaborada pelos engenheiros matemáticos Shannon e Weaver; avançam em direção aos Estudos Funcionalistas que investigam a estrutura e a função da comunicação na sociedade, principalmente nos estudos produzidos por H. Lasswell; e prosseguem nas investigações dos efeitos até chegarem à Teoria do Agendamento.

Mesmo havendo certo consenso no que se refere à tradição da pesquisa comunicacional, há os que acreditam ser impossível reunir todo o conhecimento acumulado ao longo do tempo e promover "[...] uma sistematização orgânica desses conhecimentos num conjunto co- erente" (WOLF, 2001, p. 14). Essa é, sem dúvida, a maior dificuldade em definir um quadro teórico capaz de apoiar uma pesquisa que tenha por objetivo explicar a intervenção das estruturas institucionais e de suas estratégias nas ações ligadas à atividade jornalística.

E justamente por buscarmos desvendar estratégias políticas e escolhas econômicas na ação dos veículos de comunicação de massa, é que devemos construir um referencial teórico apoiado nos estudos sociológicos de Max Weber, tendo em vista a sua contribuição para a compreensão dos fenômenos midiáticos no século XX. Weber é, sem dúvida, uma voz que não pode ser ignorada quando nos dedicamos a construir um método interpretativo que nos leve à compreensão de questões fundamentais ligadas à sociedade ocidental, como as formas de dominação utilizadas pelo Estado e a construção dos mecanismos de racionalização do trabalho, incluindo a evolução dos modelos empresariais. No que se refere à pesquisa sobre a imprensa, ele foi capaz de antever muitas das questões com que os teóricos iriam se defrontar a partir da segunda metade do século XX.

Ele chegou a sugerir pesquisas que tivessem como objeto a mídia, a produção social da notícia e que buscassem compreender como esse processo promove uma tensão entre espaço público e espaço privado. E defendeu que a Sociologia também se dedicasse a olhar, com rigor metodológico, para os fenômenos ligados à imprensa.

Em uma apresentação feita durante o Primeiro Congresso da Associação Alemã de Sociologia, em Frankfurt, em 1910, Weber atribui à imprensa o "tipo específico do âmbito público", reconhecendo que a imprensa responde, em grande parte, pela construção de uma espécie de espaço público, além de estabelecer relações de poder a partir da capacidade que tem de tornar públicos certos temas e questões. E avança, chamando a atenção para os contatos dos jornais com os partidos e com o mundo dos negócios:

Os contatos dos jornais com os partidos, aqui e em outros países, seus contatos com o mundo dos negócios, com todos os inumeráveis grupos e pessoas que influem na vida pública e são influenciados por ela, supõem um campo impressionante para a investigação sociológica explorado até agora somente em alguns de seus elementos (WEBER, 2002, p. 187).

É interessante notar que Weber se refere à necessidade de constante aumento de capital por parte dos 
jornais e questiona se esse aumento significaria também um aumento de poder que permitiria moldar a opinião pública arbitrariamente. E avança sobre um tema que nos parece central em relação à nossa pesquisa: "O que significa o desenvolvimento capitalista no interior da própria imprensa para a posição sociológica da imprensa em geral, para o papel que desempenha na formação da opinião pública?” (WEBER, 2002, p.190).

E destaca ainda que os grandes jornais têm um caráter diferente dos outros, que essa diferença é provocada basicamente pelos seus arranjos empresariais e, possivelmente, teria um impacto na formação da opinião pública, o que torna a ação da imprensa ainda mais interessante do ponto de vista da investigação sociológica.

Weber indica que as respostas para as questões que formula a respeito da imprensa, sua influência sobre a sociedade e os deslocamentos que produz, estão nos próprios jornais, naquilo que publicam sob a forma de notícia "e aquilo que já não se publica" (WEBER, 2002, p. 193). E recomenda que se estude o estilo e a aparente ausência da emoção, como forma de nos aproximarmos de "questões de maior alcance".

Apesar de Weber não mencionar especificamente as questões relacionadas à ação política da imprensa, às suas escolhas estratégicas e às alianças entre as forças políticas e os donos da mídia, estamos convencidos de que esse é, sem dúvida, um tema que merece ser investigado e que encontra nas ideias e preocupações de Max Weber sobre a imprensa, o capitalismo e a evolução histórica dos modelos empresariais um indicador seguro para fazer avançar esse conhecimento.

\section{Imprensa e capitalismo}

Entender a relação entre a imprensa e o capitalismo como forma de organização econômica é essencial para pesquisas que tenham o jornalismo como objeto. Por isso vamos buscar apoio na visão de Weber sobre o capitalismo. Para ele, o que caracteriza a ação capitalista é a expectativa do lucro, o que somente é possível a partir da organização racional das empresas, ou seja, do cálculo e do registro de sua movimentação financeira.

Ao estabelecer que a imprensa (em termos sociológicos) “[...] é necessariamente uma empresa capitalista e privada”, Weber indica que não é possível compreender o papel e ação da imprensa sem levar em conta sua natureza econômica, sua organização e suas estratégias para alcançar o lucro.

Se considerarmos a imprensa em termos sociológicos, o fundamental para toda a discussão é o fato de que, hoje em dia, a imprensa é necessariamente uma empresa capitalista e privada que, ao mesmo tempo, ocupa uma posição totalmente peculiar, posto que, ao contrário de qualquer outra empresa, tem dois tipos completamente distintos de "clientes": os primeiros são os compradores do jornal e estes compõem-se ou de uma massa majoritária de assinantes ou de uma massa majoritária de compradores individuais (...); os segundos são os anunciantes, e entre esse leque de clientes produzem-se as interrelações mais curiosas (WEBER, 1992, p. 188).

Ao relacionar as características das empresas editoras (ele se referia aos jornais alemães da época), Weber destaca a crescente necessidade de capital e questiona se essa demanda por capital não significaria um aumento de poder que permitiria à imprensa ampliar sua influência junto à opinião pública. E especula se a volubilidade dos jornais (ele usa como exemplo as mudanças de posição do Le Figaro em relação ao caso Dreyfuss) não teria relação com os altos investimentos feitos pelas empresas midiáticas e a necessidade de recuperá-los a fim de manterem-se financeiramente saudáveis. (WEBER, 2002, p. 189).

Weber aponta, ainda, como questão vital para o entendimento do papel da imprensa na sociedade a existência de grandes "trusts" midiáticos, verdadeiros impérios e o que isso significaria para a formação da opinião pública. Weber destaca que os veículos ligados a grandes consórcios têm um "caráter diferente dos outros". Com isso, Weber acreditava que o desenvolvimento capitalista da imprensa certamente teria uma influência bastante significativa na posição sociológica da imprensa em geral, e naquilo que ela significa para a formação da opinião pública, (WEBER, 2002, p. 190)

Apesar de Weber ter levantado essas relevantes questões no início do século XX, a economia do jornalismo ainda é um domínio largamente inexplorado, um objeto de estudo esquecido. O que é difícil de compreender, tendo em vista que enquanto atividade social, o jornalismo se presta logicamente a uma abordagem de natureza econômica, como afirmam Augey e Rebillard em seu texto "La dimension économique du journalisme" (2009). Mesmo não sendo totalmente ausente, a abor- 
dagem econômica nos estudos sobre o jornalismo ainda se dá de maneira periférica, restrita às análises que buscam entender o funcionamento organizacional das empresas. Prevalecem duas vertentes nesse tipo de pesquisa: uma abordagem econômica mais tradicional e os estudos voltados para a análise sociológica da economia das mídias.

A primeira das vertentes, ainda de acordo com Augey e Rebillard (2009), se dá a partir das ciências econômicas com o interesse de entender como operam as indústrias imateriais e da informação. Nesse sentido, se ocupam em explicar o funcionamento desses setores a partir de uma perspectiva econômico-industrial, quantitativa, analisando suas estruturas de custo, detalhando as características do mercado, tais como a audiência e o mercado publicitário para explicar a natureza das informações que produzem.

Já a abordagem sociológica das mídias trata das particularidades envolvidas na industrialização das obras de arte e se apoia em modelos teóricos de análise que procuram dar conta de cada uma das modalidades desses produtos: a música, o livro, o cinema, o jornalismo, o rádio e a TV. (AUGEY; REBILLARD, 2009). Trata-se, portanto, de uma visão que privilegia a economia política das mídias e que busca explicar as implicações sociais e políticas da mercantilização das obras de arte e do jornalismo. Dessa forma, é possível destacar as relações complexas entre as estruturas de financiamento das mídias e a construção de um discurso midiático que tenha credibilidade. Essa opção se coaduna perfeitamente com os objetivos das pesquisas, cujo interesse maior reside em encontrar elementos que permitam relacionar a linha editorial dos veículos de grandes impérios midiáticos brasileiros às suas estruturas de financiamento e apoio político, evidenciando, assim, que a política editorial desses veículos se apoiaria em uma ação política de seus proprietários.

Seria possível, então, estabelecer um modelo de análise que apontasse com segurança as escolhas e iniciativas de Chateaubriand e Marinho no campo editorial (artigos, manchetes, notícias, fotografias e tudo o mais que compõe a produção de informação jornalística) e que estivesse diretamente relacionado às estratégias formuladas, visando garantir e reforçar suas estruturas de financiamento. A economia, enquanto campo científico, não se constitui a partir de uma visão homogênea. Ao contrário (e a exemplo da própria comunicação), resulta do encontro de uma diversidade significativa de saberes, principalmente no que se refere às metodologias empregadas em suas pesquisas. $\mathrm{O}$ que garante certa coerência e dá alguma unidade aos seus interesses é o fato de que a economia tem na prática humana uma referência fundamental.

Sendo assim, as ações individuais, as escolhas, os limites e os objetivos dos atores envolvidos são determinantes para a compreensão dos fenômenos econômicos em evidência. Para relacionar as ações individuais aos resultados econômicos, os economistas acabaram por desenvolver modelos de análise baseados no comportamento. Daí surgiu uma disciplina, a princípio denominada "Economia da Informação" e que, nos últimos 20 anos, ganhou fôlego a partir dos estudos desenvolvidos principalmente nos Estados Unidos e que Augey e Rebillard preferem chamar de "Economia das Mídias".

E quais são os problemas relacionados ao campo midiático que interessam a essa disciplina? Basicamente, a economia das mídias vai compor o referencial teórico para estudos relativos à concentração midiática - condição que limita a diversidade, o pluralismo e o alcance do discurso midiático; ou ainda, sobre a existência de uma tendência ideológica nas mídias e qual a maneira de apontar essa tendência. A partir do seu modelo de gestão econômica ou pela ação política de seu proprietário?

O estudo da economia das mídias permite, ainda, definir que tipo de influência as mídias exercem sobre os processos decisórios utilizados pela sociedade. Por exemplo: podemos relacionar liberdade midiática ao crescimento econômico? Ou podemos investigar de que maneira a liberdade das mídias se constitui em um fator inibidor da corrupção?

Por tudo isso, parece-nos bastante apropriado utilizar como referencial teórico de nossa pesquisa a abordagem sociológica da mídia proposta por Max Weber, aprofundando as análises do papel desempenhado nas relações de poder do jornalismo com a sociedade. E isso pode ser feito não apenas a partir do estudo de suas características empresariais, ditadas por seu caráter capitalista, mas também a partir da observação dos seus discursos, evidenciados em seus modelos de gestão ou pelo comportamento de seus proprietários, como definem os conceitos desenvolvidos pela economia das mídias. 


\section{Definindo um método}

Na pesquisa científica, o método é a garantia de que o papel social da ciência prevalecerá sobre os interesses ou visões de mundo dos pesquisadores. Um método coerente e claro é condição fundamental para que se possa atribuir valor científico a qualquer estudo ou observação da realidade. Compete à metodologia criar conceitos úteis e específicos que nos orientem e nos auxiliem em nossa aproximação aos fenômenos pelos quais temos interesse. No caso das pesquisas que envolvem o campo do jornalismo, estamos lidando com eventos influenciados pela "convivência social" e pelas "configurações culturais".

A ciência social que pretendemos exercitar é uma ciência da realidade. Procuramos entender na realidade que está ao nosso redor, e na qual nos encontramos situados, aquilo que ela tem de específico, por um lado, as conexões e a significação cultural das nossas diversas manifestações na sua configuração atual e, por outro, as causas pelas quais ela se desenvolveu historicamente de uma forma e não de outra (WEBER, 2001, p.124).

Dessa maneira, devemos buscar uma abordagem metodológica que garanta, ao mesmo tempo, que sejamos capazes de "reduzir a realidade empírica a certas leis" sem deixar de distinguir o essencial do secundário, relacionando os elementos da realidade a "valores culturais" universais, destacando as conexões que se mostram significativas. (WEBER, 2001, p. 131)

Vislumbramos na concepção de tipo ideal de Max Weber uma possibilidade metodológica capaz de permitir que nos aproximemos do nosso objeto "confrontando o real e o não-real, o idealizado e o empírico" e por meio das semelhanças, divergências e contrastes sermos capazes de "descrever, interpretar e esclarecer a realidade pesquisada." (SOUZA, 2012, p. 1).

Weber acentua que os conceitos de tipo ideal têm um sentido puramente lógico, devendo ser separados da ideia de "dever ser", do "exemplar". Também não deve ser visto como uma hipótese, mas como formadores de um "juízo de atribuição":

Obtém-se um tipo ideal mediante a acentuação unilateral de um ou de vários pontos de vista e mediante o encadeamento de grande quantidade de fenômenos isoladamente dados, difusos e discretos, que se pode dar em maior ou menor número ou mesmo faltar por completo, e que se ordenam segundo os pontos de vista unilateralmente acentuados, a fim de se formar um quadro homogêneo (WEBER, 2001, p. 137).
Sendo assim, defendemos que essas pesquisas apoiem-se em uma metodologia baseada no conceito de tipo ideal, definindo algumas categorias ideais que nos permitam descrever, interpretar e esclarecer as ações e estratégias adotadas por Chateaubriand e Marinho no sentido de estabelecer e manter as estruturas de sustentação econômica e política de suas empresas midiáticas.

Será possível, ainda, perceber de que maneira a evolução histórica da economia política brasileira interferiu na criação e no processo de consolidação dos conglomerados midiáticos analisados e que fatos, eventos e personagens foram decisivos nessa trajetória.

Da mesma forma, a utilização da tipologia ideal weberiana trará a possibilidade de destacar e relacionar as características pessoais dessas personagens que repercutiram nos resultados de suas respectivas empresas, principalmente no que se refere às diferenças fundamentais de comportamento entre eles, seus objetivos pessoais e de que forma esses objetivos se coadunavam ou não com os objetivos de suas organizações.

\section{Considerações finais}

A importância conquistada pela comunicação mediática na chamada sociedade complexa ou tecnológica influenciou o percurso da pesquisa científica no campo comunicacional. Apesar de ainda persistirem dificuldades, resistências e incompreensões, houve avanços significativos na tentativa de definir um objeto de estudo e, assim, finalmente atribuir à Comunicação a condição de disciplina.

A clareza na reflexão epistemológica do campo disciplinar em questão, que permita aos pesquisadores avançar em terreno mais sólido passa, necessariamente, por diferentes abordagens que se utilizam de outras formas de conhecimento para compreender os fenômenos ligados à comunicação humana, especialmente aqueles que se processam intermediados pela tecnologia.

Ao propor a realização de uma pesquisa históricosociológica que desvele de que maneira e sob quais condições, ao longo do século XX, surgiram no Brasil dois conglomerados econômicos que têm suas origens em empresas exclusivamente jornalísticas, capitaneados por dois personagens dotados de forte personalidade política, como Assis Chateaubriand e Roberto Marinho, acredita- 
mos poder contribuir para que a communication research aprofunde seus conhecimentos a respeito da economia política dos meios de comunicação, definindo com clareza um objeto de estudo específico para a comunicação. Para que essa pesquisa se sustente, do ponto de vista da sua fundamentação teórica, vislumbramos nas ideias de Max Weber sobre a sociologia da mídia um instrumento capaz de apontar uma possibilidade de diálogo com o objeto que nos permita avançar, com a necessária segurança epistemológica exigida em um trabalho científico, em direção à compreensão dos fenômenos e dos fatos que motivaram tal projeto.

Os conceitos que encontramos na disciplina "Economia da Mídia”, bem como as ferramentas metodológicas a serem desenvolvidas a partir da tipologia ideal de Weber, permitirão estabelecer uma tentativa cientificamente válida de compreender as relações entre a ação dos meios de comunicação (notadamente suas escolhas editoriais) e as estratégias políticas e econômicas que levaram à construção dos grandes impérios midiáticos brasileiros.

\section{Referências}

AUGEY, Dominique; REBILLARD, Franck. Introduction: la dimension économique du journalisme. Les Cahiers $d u$ Journalisme, Paris, n. 20, p.10-21

CABRAL, Eula Dantas Taveira. O negócio da mídia brasileira: suas estratégias, suas políticas. In: ENCONTRO DOS GRUPOS/NÚCLEOS DE PESQUISAS EM COMUNICAÇÃO, 9., 2009, Curitiba. GP políticas de comunicação e cultura. Curitiba: Intercom, 2009.
MARTINO, Luiz C. As Epistemologias contemporâneas e o lugar da comunicação. In: LOPES, Maria Immacolata Vassalo (Org.). Epistemologia da comunicação. São Paulo: Loyola, 2003.

MARTINO, Luiz C. Abordagens e representação do campo comunicacional. Comunicação, Mídia e Consumo, São Paulo, v. 3, n. 8, p. 33-54, nov. 2006.

MORAIS, Fernando. Chateau: o rei do Brasil. São Paulo: Companhia das Letras, 1995.

POPPER, K. A lógica da pesquisa científica. 16. ed. São Paulo: Cultrix, 2008.

SILVA, Carlos Eduardo Lins da. Muito além do Jardim Botânico: um estudo sobre a audiência do Jornal Nacional da Globo entre trabalhadores. São Paulo: Summus, 1985.

SOUZA, Sérgio Alves. Uma aplicação dos tipos ideais weberianos. Disponível em: <http://www.ufpe.br/gepec/ exemplos/06_artigo03\% 28sergioalves\%29.pdf >. Acesso em: 09 set. 2012.

TASCHNER, Gisela. Folhas ao vento: análise de um conglomerado jornalístico no Brasil. Rio de Janeiro: Paz e Terra, 1992.

WEBER, Max. Sociologia da imprensa: um programa de pesquisa. Lua Nova, São Paulo, n. 55-56, p. 185-194, 2002.

WEBER, Max. A ética protestante e o espírito do capitalismo. 2. ed. São Paulo: Pioneira Thomson Learning, 2003.

WEBER, Max. Metodologia das ciências sociais. São Paulo: Cortez, 2001.

WOLF, Mauro. Teorias da comunicação. 6. ed. Lisboa: Presença, 2001. 